\title{
Awareness about expressed breast milk feeding among working mothers visiting a tertiary level hospital, Kathmandu
}

\section{Pandey S}

Shrijana Pandey, Lecturer, Department of Nursing, Kathmandu Medical College, Kathmandu, Nepal.

\begin{abstract}
Background: Expressed breast milk can be a healthy feeding option as compared to formula for working mothers. A large number of mothers are working these days and despite their desire to breastfeed, mothers have to get back to their work because of various constraints.

Objectives: The research objective was to assess the status of knowledge and attitude regarding expressed breastfeeding and to identify the barriers to expressed breastfeeding among working mothers visiting Kathmandu Medical College Teaching Hospital.

Methodology: A cross-sectional study was conducted at Pediatric Outpatient Department of Kathmandu Medical College Teaching Hospital from June 2018 till December 2018. One hundred and eighty working mothers were chosen purposively and interviewed. Research instrument was a structured questionnaire containing questions about technique of pumping and storing breast milk, benefits of breastfeeding, attitude regarding expressed breastfeeding and reasons for not expressing breast milk. Mean standard deviation and Chi-square tests were used for statistical analysis.

Results: Out of 180 mothers, half of the mothers had adequate knowledge regarding expressed breastfeeding while slightly more than half of them (52.2\%) had negative attitude about it. Only $11.7 \%$ of the mothers shared that they had expressed breast milk ever. The most important reason for not expressing breast milk was stated to be inadequate breast milk production $(30.7 \%)$ and lack of time $(26.4 \%)$.

Conclusion: The study concludes that about half of the working mothers have adequate knowledge and positive attitude regarding expressed breastfeeding. Moreover, very few mothers ever expressed breast milk and the main reason for not doing so was inadequate milk production.
\end{abstract}

Key words: Awareness; Barriers; Expressed breastfeeding; Working mothers

DOI: https://doi.org/10.3126/jkmc.v8i2.28165

\section{INTRODUCTION}

$\mathrm{B}$ reastfeeding is advantageous to both mothers and infants. It decreases common infant problems like colic and diarrhea. It also helps mother to get back to her pre-pregnancy weight and aids in uterine involution. Exclusive breastfeeding for up to six months and complementary food along with breastfeeding for up to 2 years is the optimal way to feed infants ${ }^{1}$.

There are a lot of barriers to successful breastfeeding and mother's employment has been reported to be a major constraint as workplace doesn't provide enough support to them many times ${ }^{2,3}$. Research finding from a

Address for correspondence

Ms. Shrijana Pandey

Lecturer, Department of Nursing

Kathmandu Medical College, Sinamangal, Kathmandu

E-mail: srijanapdy@gmail.com longitudinal study carried out in Australia has reported that maternal employment in first six months of baby's life leads to premature cessation of breastfeeding ${ }^{4}$. Though World Health Organization (WHO) has recommended that every mother require long maternity leave and increase in benefits ${ }^{5}$ it is still not present in common practice. To cut down these work related difficulties, a large number of working mothers have started to express their breast milk and give it to their babies ${ }^{2,6}$. There are various techniques of expressing breast milk; the two common techniques are manual expression or expression using electrical pumps. Research study suggest that working women who wish to continue breastfeeding even after getting back to work can use electric pumps to express their breast milk and thus expressed milk can be stored for up to 8 hours at room temperature ${ }^{7}$. Expression of breast milk has also been reported to develop a sense of emotional connection between babies who are apart from their mother due 
to various reasons ${ }^{8}$. Furthermore, mothers who express breast milk have been found to continue breast feeding for at least six months than those who never expressed ${ }^{9}$. And for all these reasons, expressing breast milk has been proven to be a boon to both mothers and infants ${ }^{10}$.

In developing countries like Nepal, where paid maternity leave for working mothers is only 98 days ${ }^{11}$ exclusive breastfeeding for six months is very difficult. Expressed breastfeeding could be one possible alternative to continue breastfeeding even after resuming work but awareness regarding this option is still low. A study carried out in Nepal revealed that only $12 \%$ of mothers had knowledge regarding expressing breast milk while only $8.3 \%$ practiced $\mathrm{it}^{12}$. This signifies that there is a huge lag in knowledge as well as practice of mothers regarding expressed breast milk feeding. This study aimed to assess knowledge, attitude and barriers to expressed breast milk feeding among working mothers visiting a tertiary hospital in Nepal.

\section{METHODOLOGY}

A descriptive cross-sectional study using purposive sampling was carried out to assess the awareness of expressed breast milk feeding among 180 working mothers. Taking the prevalence of knowledge regarding expressed breast milk as $12 \%^{12}$ the respondents were recruited using formula $n=z^{2} p q / d^{2}(d=0.05, z=1.96$, $\mathrm{p}=0.12$ and $\mathrm{q}=0.88$ ).

In the study, all the mothers who worked outside of the house for at least 6 continuous hours per day were defined as working mothers. The working mothers who attended Pediatric Outpatient and Well baby clinic of Kathmandu Medical College and Teaching hospital with infants of up to 2 years of age were included in the study. The independent study variables included in the study were socio-demographic information of the mother and child while the dependent variables were knowledge and attitude regarding expressed breastfeeding. Data was gathered using face-to-face interview from June to December 2018.

The research instrument consisted of questions related to socio-demographic information, knowledge regarding techniques of pumping and storing expressed breast milk, benefits of breastfeeding to mother and baby, attitude towards expressed breast feeding, experience of expressed breast feeding and reasons for not expressing breast milk. The tool was developed by the researcher after thorough literature review and expert's suggestions. The tool was pretested among those working mothers who visited pediatric outpatient of Kathmandu Medical College and Teaching Hospital but didn't add to the final sample of the study. Necessary modifications were made in the questionnaire after pretesting. The validity of the tool was ensured through extensive literature review and consultation with subject experts and colleagues.

Collected data was edited, coded and entered into Statistical Package for Social Sciences (SPSS) software-20. Mean, standard deviation, frequency and percentage were calculated for descriptive analysis while Chi-Square test was carried out to test the association between variables. The questionnaire consisted of 24 questions in total to assess the knowledge regarding expressed breast feeding:10 questions related to technique and storage of expressed breast milk, 10 questions related to benefits of breast feeding to mothers and infant and remaining 4 questions about lactation. Each of these 24 questions was a single response question. Similarly, for assessing the attitude of mothers regarding expressed breastfeeding, a five point Likert scale was developed which consisted of 16 statements regarding feelings and beliefs related to expressed breastfeeding. The highest possible score for knowledge was 24 and that for attitude was 80 . The mean of total knowledge and attitude score was used to categorize mothers as having adequate/inadequate knowledge and positive/negative attitude respectively. Mothers scoring less than mean score were classified as having inadequate knowledge and negative attitude while those who obtained scores more than or equal to mean were categorized as having adequate knowledge and positive attitude.

Ethical approval was obtained from Institutional Review Committee of Kathmandu Medical College. Permission was obtained from head of the department of pediatrics and written informed consent was obtained from all the mothers included in the study. The mothers were given full authority to withdraw their participation from the study without any fear or clarification any time during the interview. Confidentiality was maintained by using code numbers to identify the mothers.

\section{RESULTS}

The mean age of the mothers was 29.6 years while that of children was 10.4 months. The mean age of the child when mother resumed work was 4.48 months. More than three-fourth of the mothers were from Kathmandu and about $62 \%$ lived in joint/extended family. Thirtyseven percentages of mothers had obtained graduate degree and $37.8 \%$ of them were Brahmin. More than half $(56.7 \%)$ of mothers were involved in service and slightly more than half of the children were male. The median 
family income of the mothers was 60,000 Nepali Rupees. There was a large variation in the range of income i.e. NRs. 12000 to NRs. 900000 (Table 1).

About half of the respondents had adequate overall knowledge regarding expressed breastfeeding while more than half of the mothers (52.2\%) had negative attitude towards expressed breast milk feeding (Table 2).

Ethnicity and occupation of mothers was found to be significantly associated with the level of knowledge regarding expressed breastfeeding $(p=0.035$ and $p=\leq 0.001$ respectively). No statistically significant associations were noted between residence of mothers, type of family, educational level, sex of the child and knowledge regarding expressed breastfeeding (Table 3).

Educational level of mothers, ethnicity, occupation and sex of the child was found to be significantly associated with attitude regarding expressed breastfeeding ( $p=0.029, p=0.017, p=0.008$ and $p=0.048$ respectively). Place of residence and type of family, however, didn't have any significant association with attitude about expressed breastfeeding (Table 3).

\section{Reasons for not expressing breast milk}

The study showed that $11.7 \%$ of mothers were expressing or expressed breast milk at certain point after the delivery of the baby. In respect to reasons for not expressing, $30.7 \%$ of the mothers shared inadequate breast milk production as a reason for not expressing breast milk. Other reasons stated by the mothers included lack of time $(26.4 \%)$, feeling that child doesn't like the taste of it (16.5\%), insufficient knowledge regarding expressing technique (16\%), logistic inconveniences like no privacy at workplace, unavailability and high expense of breast pumps (16\%) and belief that expressing is an unhealthy practice (16\%).

Table 1: Socio-demographic Characteristics of the Respondents $(n=180)$

\begin{tabular}{|c|c|c|}
\hline Socio-demographic Variables & Frequency & Percentage \\
\hline \multicolumn{3}{|l|}{ Residence } \\
\hline Kathmandu & 141 & 78.3 \\
\hline Bhaktapur & 25 & 13.9 \\
\hline Lalitpur & 5 & 2.8 \\
\hline Outside of Kathmandu Valley & 9 & 5.0 \\
\hline \multicolumn{3}{|l|}{ Family type } \\
\hline Nuclear & 69 & 38.3 \\
\hline Joint/extended & 111 & 61.7 \\
\hline \multicolumn{3}{|l|}{ Educational Status } \\
\hline Less than or equal to high school & 58 & 32.2 \\
\hline Graduate & 66 & 36.7 \\
\hline Post graduate and higher & 56 & 31.1 \\
\hline \multicolumn{3}{|l|}{ Ethnicity } \\
\hline Brahmin & 68 & 37.8 \\
\hline Chhetri & 47 & 26.1 \\
\hline Janajati & 55 & 30.6 \\
\hline Others & 10 & 5.6 \\
\hline \multicolumn{3}{|l|}{ Occupation } \\
\hline Service & 102 & 56.7 \\
\hline Business & 29 & 16.1 \\
\hline Health services & 43 & 23.9 \\
\hline Student & 5 & 2.8 \\
\hline Farming & 1 & 0.6 \\
\hline \multicolumn{3}{|c|}{$\begin{array}{l}\text { Median family income = NRs. } 60,000 \\
\text { (Range= NRs. } 12000-900000)\end{array}$} \\
\hline \multicolumn{3}{|l|}{ Sex of the child } \\
\hline Male & 95 & 52.8 \\
\hline Female & 85 & 47.2 \\
\hline
\end{tabular}


Table 2: Knowledge and Attitude Regarding Expressed Breast Feeding

\begin{tabular}{lcc|}
\hline Knowledge & Frequency & Percentage \\
\hline Overall Knowledge & & 50.6 \\
\hline Inadequate & 91 & 49.4 \\
\hline Adequate & 89 & \\
\hline Mean knowledge score= $16.378 \pm 3.169$ & & 47.2 \\
\hline Knowledge regarding storage and expression of breast milk & 85 & 52.8 \\
\hline Inadequate & 95 & 36.1 \\
\hline Adequate & & 63.9 \\
\hline Knowledge about lactation and its benefits & 65 & 115 \\
\hline Inadequate & & 47.8 \\
\hline Adequate & 86 & 52.2 \\
\hline Attitude regarding expressed breast feeding & 94 & \\
\hline Positive & & \\
\hline Negative & & \\
\hline Mean attitude score= $54.367 \pm 10.345$ & & \\
\hline
\end{tabular}

Table 3: Association between independent variables and knowledge and attitude regarding expressed breast feeding

\begin{tabular}{|c|c|c|c|c|c|c|}
\hline \multirow[t]{2}{*}{ Variables } & \multicolumn{2}{|c|}{ Level of knowledge } & \multirow[t]{2}{*}{ p-value } & \multicolumn{2}{|c|}{ Attitude } & \multirow[t]{2}{*}{ p-value } \\
\hline & Inadequate & Adequate & & Positive & Negative & \\
\hline \multicolumn{7}{|l|}{ Residence } \\
\hline Inside of valley & 85 & 86 & \multirow{2}{*}{0.321} & 83 & 88 & \multirow{2}{*}{0.373} \\
\hline Outside valley & 6 & 3 & & 3 & 6 & \\
\hline \multicolumn{7}{|l|}{ Family type } \\
\hline Nuclear & 7 & 35 & \multirow{2}{*}{0.787} & 36 & 33 & \multirow{2}{*}{0.352} \\
\hline Joint/Extended & 84 & 54 & & 50 & 61 & \\
\hline \multicolumn{7}{|l|}{ Education } \\
\hline Graduate & 65 & 59 & \multirow{2}{*}{0.457} & 66 & 58 & \multirow{2}{*}{$0.029^{*}$} \\
\hline Postgraduate or higher & 26 & 30 & & 20 & 36 & \\
\hline \multicolumn{7}{|l|}{ Ethnicity } \\
\hline Brahmin & 26 & 42 & \multirow{4}{*}{$0.035^{*}$} & 25 & 43 & \multirow{4}{*}{$0.017^{*}$} \\
\hline Chhetri & 30 & 17 & & 28 & 19 & \\
\hline Janajati & 31 & 24 & & 25 & 30 & \\
\hline Others & 4 & 6 & & 8 & 2 & \\
\hline \multicolumn{7}{|l|}{ Occupation } \\
\hline Health related & 7 & 36 & \multirow{2}{*}{$\leq 0.001^{*}$} & 73 & 64 & \multirow{2}{*}{$0.008^{*}$} \\
\hline Non-health related & 84 & 53 & & 13 & 30 & \\
\hline \multicolumn{7}{|l|}{ Sex of the child } \\
\hline Male & 54 & 41 & \multirow{2}{*}{0.075} & 52 & 43 & \multirow{2}{*}{$0.048^{*}$} \\
\hline Female & 37 & 48 & & 34 & 51 & \\
\hline
\end{tabular}

*Chi-square p value significant at $\leq 0.05$

\section{DISCUSSION}

The study showed that half of the mothers had adequate knowledge regarding expressed breastfeeding while the other half had inadequate knowledge. Another study done in Nepal among mother of infants reported that only $12 \%$ of the mothers had knowledge regarding expressed breast feeding ${ }^{12}$. Similarly, other research studies done worldwide have shown that knowledge regarding expressed breast feeding was as low as 13 $\%^{13}$ to $36 \%$ among working mothers ${ }^{14}$. This reflects that knowledge regarding expressed breastfeeding among working mothers included in this study is better than those in reviewed studies. In the present study, slightly less than half of the mothers had positive attitude towards expressed breast feeding which is similar to the findings of a study where $40 \%$ of mothers had positive 
towards expressing breast milk ${ }^{14}$. In this study, only $11.7 \%$ of working mothers ever expressed breast milk which is very low (33.7\% in Nigeria) as compared to studies done elsewhere ${ }^{13}$. The reason for lower practice percentage in Nepal may be due to unfavorable work environment, lack of trust in the procedure of expressing breast milk and ignorance about the practice of expressing breast milk.

The study revealed that ethnicity has significant association with knowledge and attitude regarding expressed breastfeeding. This finding infers that there are variations in level of awareness among mothers belonging to different ethnicities. In the study, occupation of mother is found significantly associated with knowledge and attitude regarding expressed breastfeeding. The association maybe because the present study included a fair number of mothers working in health related sectors like nursing, public health and medicine. Research study has reported that health professionals are more aware of breastfeeding as they learn about various aspects of breastfeeding as a part of their study ${ }^{15}$. Similarly, educational status was found significantly associated with attitude towards expressed breastfeeding in the study which is similar to the finding of a study where mother with higher level of educational status has been reported to have good overall knowledge and practice regarding breastfeeding ${ }^{16}$. In the study, sex of the child was found to have significant association with attitude towards expressed breastfeeding which is not in agreement with the findings of other studies ${ }^{17}$. The disagreement of the findings may be because of random fluctuations.

\section{REFERENCES}

1. World Health Organisation. WHO | Breastfeeding[Internet]. Geneva:WHO.2019[Cited 2019, January 2]. [DOI]

2. Labiner-Wolfe J, Fein SB, Shealy KR, Wang C. Prevalence of Breast Milk Expression and Associated Factors. Pediatrics[Internet].2008. [Cited 2018, December 8] 122(Suppl 2):S63-S68. [Full text]

3. Witters-Green R. Increasing Breastfeeding Rates in Working Mothers. Fam Syst Heal. 2003;21(4):415434. doi:10.1037/h0089617 [DOI]

4. Cooklin AR, Donath SM, Amir LH. Maternal employment and breastfeeding: Results from the longitudinal study of Australian children. Acta Paediatr Int J Paediatr. 2008 May;97(5):620-623. doi:10.1111/j.1651-2227.2008.00740.x [PubMed]
The study revealed that inadequate milk production and time were major constraints that prevented mothers from expressing breast milk while study done abroad has reported that lack of knowledge regarding expressing technique and a feeling that baby has a right to feed from the breast are important barriers to expressing breast milk ${ }^{13,14,18}$. The current research focused on a relatively unstudied aspect of breastfeeding and helped in identifying the barriers faced by a large number of mothers who work outside of the house these days. However, the study was conducted in only one set up using purposive sampling which limits the generalizability of the obtained findings.

\section{CONCLUSION}

The study concludes that status of knowledge and attitude regarding expressed breastfeeding among working mothers is on an average adequate and positive respectively. Moreover, very few working mothers ever express breast milk despite having adequate knowledge and positive attitude. Inadequate milk production and timeare important barriers to expressing breast milk among working mothers.

\section{ACKNOWLEDGEMENTS}

The researcher would like to thank all the mothers included in the study for giving their valuable time. Researcher also wishes to thank all the staffs of pediatric department of Kathmandu Medical College and Teaching Hospital for their help and support during the time of data collection.

5. World Health Organisation. Infant and young child feeding[Internet]. Geneva: WHO. 2019 [Cited 2019 January, 15]. [DOI]

6. Ortiz J, McGilligan K, Kelly P. Duration of breast milk expression among working mothers enrolled in an employer-sponsored lactation program. Pediatr Nurs[Internet]. 2004 Mar-Apr [Cited 2018 October,5] ;30(2):111-119. [PubMed]

7. Biagioli F. Returning to Work while Breastfeeding. Am Fam Physician[Internet].2003 Dec [Cited 2018 December,11];68(11):2201-2208+2215. [PubMed]

8. Sweet L. Expressed breast milk as "connection" and its influence on the construction of "motherhood" for mothers of preterm infants: A qualitative study. Int Breastfeed J. 2008 Dec;3:1-12. doi:10.1186/17464358-3-30 [DOI] 
9. Win NN, Binns CW, Zhao Y, Scott JA, Oddy WH. Breastfeeding duration in mothers who express breast milk: A cohort study. Int Breastfeed J. 2006 Dec;1:1-5. doi:10.1186/1746-4358-1-28 [PubMed]

10. Rasmussen KM, Geraghty SR. The quiet revolution: Breastfeeding transformed with the use of breast pumps. Am J Public Health. 2011 Aug;101(8):13561359. doi:10.2105/AJPH.2011.300136 [PubMed]

11. Government of Nepal, Ministry of Labour, Employment and Social Security.Labour Act 2074 [Internet].Minbhawan, Baneshwor:Department of Labour and Occupational Safety; $4^{\text {th }}$ September, 2017. [Cited 2019 June 22]. [Full text]

12. Adhikari T, Subedi I. Knowledge and Practice on Breastfeeding among Mothers of Infant. J Food Sci Technol Nepal. 2013;8(0):71-74. doi:10.3126/jfstn. v8i0.11754 [DOI]

13. Attahiru A, Awosan KJ, Oche MO, Kaoje AU, Yusuf T, Ango UM. Breastfeeding Support and Determinants of Expressed Breast Milk Feeding Practice among Working Mothers in Sokoto, Nigeria Section: Community Medicine. International Journal of Contemporary Medical Research. 2018;5(8):1-8. [Full text]
14. Rai S. Expressed breast milk: a less used option by working mothers of India. Int J Reprod Contraception, Obstet Gynecol. 2017;6(7):2874. doi:10.18203/23201770.ijrcog20172603 [Full text]

15. Yang SF, Salamonson Y, Burns E, Schmied V. Breastfeeding knowledge and attitudes of health professional students: a systematic review. Int Breastfeed J. 2018 Feb;13(1):8. doi:10.1186/s13006018-0153-1 [PubMed]

16. Roshan R, Sajjad S, Tanvir S. Impact of maternal education and source of knowledge on breast feeding practices in Rawalpindi city. MOJCRR. 2018. doi:10.15406/mojcrr.2018.01.00035 [DOI]

17. Mohammed BA, Soliman SA. Mothers' Attitudes toward Breastfeeding and Their Association with Infants' Characteristics. J Nurs Heal Sci. 2018;7(3):6069. doi:10.9790/1959-0703036069 [Full text]

18. Chege PM, Ndungu ZW. Research Article Expressing Breast Milk: Constraints Among Working Lactating Mothers in Nairobi, Kenya. International Journal of Current Advanced Research. 2016 Oct ;5(10):13971399. [Full text] 